\title{
La cooperación económica y la reformulación de la política económica peronista, 1949-1955
}

\section{The economic cooperation and the reformulation of the Peronist economic policy, 1949-1955}

\author{
Leandro Sowter ${ }^{1, *}$ (D) 0000-0002-9305-5056 \\ ${ }^{1}$ Centro de Estudios de Historia Económica Argentina y Latinoamericana, Universidad de Buenos Aires, Buenos Aires, Argentina. \\ *Correspondencia: leandrosowter@yahoo.com.ar
}

Resumen. El presente artículo trata sobre la cooperación económica entre 1949 y 1955, política ejecutada a través de consejos y comisiones que buscó involucrar a empresarios y trabajadores en la política económica. Se argumenta que, con el objetivo de administrar los costos políticos que supuso el ajuste en la economía a partir de 1949, el gobierno diseñó una estrategia que llevó a fortalecer la cooperación económica y la participación de los actores. Con base en una variedad de fuentes que recuperan las discusiones tripartitas en los consejos y comisiones, se muestra que la agenda de la cooperación económica varió en su densidad y profundidad: desde precios y salarios hasta la productividad.

Palabras clave: peronismo; política económica; consejos económicos; corporaciones; concertación.

Abstract. This article deals with economic cooperation between 1949 and 1955, a policy executed through councils and commissions that sought to involve businessmen and workers in economic policy. It is argued that, with the objective of managing the political costs of the adjustment in the economy since 1949, the government designed a strategy that led to strengthening economic cooperation and the participation of

CÓMO CITAR: Sowter, L. (2021). La cooperación económica y la reformulación de la política económica peronista, 1949-1955.

América Latina en la Historia Económica, 28(3), 1-22. DOI: 10.18232/alhe.1196 
the actors. Based on a variety of sources that recover tripartite discussions in councils and commissions, it is shown that the agenda of economic cooperation varied in its density and depth: from prices and wages to productivity.

Key words: peronism; economic policy; economic councils; corporations; concertation.

JEL: N16; N46.

Recibido: 20 de abril de 2020.

Aceptado: 09 de diciembre de 2020.

Publicado: 26 de mayo de 2021.

\section{INTRODUCCIÓN}

La crisis económica de los años 1949-1952 puso en jaque el modelo económico, distributivo y de relaciones laborales que el peronismo impulsaba desde 1946, al tiempo que mostró los límites y problemas estructurales de una industrialización liviana y mercadointernista. Por fuerza de las circunstancias, el gobierno debió introducir modificaciones políticas, económicas y burocráticas que implicaban contradicciones con su base de apoyo sindical y popular. La problemática enfrentada -cómo mantener la distribución de salarios sin atizar la inflación y cómo incentivar la inversión privada sin perder el apoyo sindical- obligó a desarrollar una estrategia política que permitiera reformular la política económica con los menores costos posibles.

La reorientación de la política económica a partir del segundo gobierno peronista (1951-1955) ha recibido aportes desde distintos enfoques. Desde el análisis de la política económica se enfatiza el "cambio de rumbo" y la "vuelta al campo" que supusieron los objetivos de priorizar la lucha contra la inflación, incentivar la productividad industrial, la producción agroexportable y las inversiones extranjeras en el marco de la etapa de consolidación de la industrialización y la promoción de sus sectores básicos (Gerchunoff y Llach, 2003; Mallon y Sourrouille, 1973; Rapoport, 2000; Rougier, 2012).

Los estudios que se focalizaron en los actores socioeconómicos analizaron cómo su comportamiento condicionó al capitalismo argentino en general y a las políticas económicas en particular. ${ }^{1}$ En el estudio del movimiento obrero hay autores que estudiaron cómo el peronismo cooptó progresivamente al sindicalismo, aunque no pudo impedir el avance de los trabajadores en la lucha económica y no siempre pudo controlar la conflictividad obrera en función de los objetivos oficiales, lo cual condicionó los resultados de las políticas estatales (Doyon, 2006; Schiavi, 2013). Asimismo, se ha puesto de relieve cómo la politización de las relaciones socioeconómicas en la emergencia del peronismo estrechó y polarizó el campo de la política, minando la legitimidad del gobierno frente a otros actores sociales y encendiendo expectativas a las que luego el gobierno debió responder (James, 2010; Sidicaro, 2002). En cuanto al empresariado, se analizaron diferentes aspectos de su relación con el gobierno, ya sea enfocándose en sus contradicciones internas y la heterogeneidad propia del sector industrial (Mainwaring, 1986; Teichman, 1981); en el carácter

${ }^{1}$ Por actores socioeconómicos entendemos a las organizaciones representativas de los trabajadores y de los empresarios, en este caso, la Confederación General del Trabajo (CGT) y la Confederación General Económica (CGE), respectivamente. 
de la lucha política intraburguesa, el comportamiento de la burguesía como actor político, la participación de los empresarios del interior y los avatares de su organización corporativa que afectaron su capacidad de acción colectiva (Acuña, 2014; Brennan y Rougier, 2009; Cúneo, 1984; Jáuregui, 2004; Rougier y Sowter, 2018).

Si bien la bibliografía avanzó considerablemente en cuanto al qué (la caracterización de la política económica) y al quiénes (la participación de los actores socioeconómicos) es relativamente incipiente la pregunta por el cómo, es decir, por la manera en que se formuló e implementó la política económica y, particularmente, por el desempeño de los actores. Autores que estudiaron el proceso de formulación e implementación de la política económica profundizaron los debates de los tomadores de decisiones o relacionaron las políticas post 1949 con las reformas burocráticas (Belini, 2014; Rougier y Stawski, 2013). Sin embargo, son pocos los estudios que trataron el problema de la cooperación económica, es decir, de la vinculación institucional de los actores socioeconómicos con la política económica. Entre quienes abordaron esta cuestión predomina un balance más bien negativo respecto de su funcionamiento y resultados. Jáuregui analiza los "consejos técnicos" que vinculaban a los empresarios con el Estado entre 1920 y 1955 y concluye que, a diferencia del caso brasileño, la participación "fue esporádica y no permitió la construcción de mecanismos permanentes” (2004, p. 51). De manera similar, en su análisis de la política industrial peronista, Belini (2014) argumenta que la burocracia trabajó de forma "aislada" y que no hubo participación o representación empresaria “orgánica” en los planes y políticas. Stawski, quien estudia los consejos económicos y la dinámica burocrática dentro de los organismos estatales durante el peronismo, sostiene que los consejos y comisiones económicas cumplieron una labor "opaca", "sin relevancia” y que "las políticas eran más bien definidas por los funcionarios públicos, que por los distintos sectores representativos de la economía” (2012, p. 262).

Otros autores, que discutieron sobre cuestiones más amplias que versan sobre la caracterización del régimen peronista y la forma que asumió el proceso de su intervención económica estatal, generaron visiones que en mayor o menor medida influyeron sobre los debates historiográficos actuales. Mientras que algunos subrayan que las ambiciones personales de Perón y el carácter manipulador o autoritario lo habría llevado a excluir a otros actores -políticos, institucionales y socioeconómicos- de las decisiones (Germani, 1968; Luna, 1986); otros enfatizan que la experiencia pluriclasista y los mecanismos corporativos del peronismo estaban condenados al fracaso habida cuenta del antagonismo de los intereses de clase (Bitrán, 1994; Peralta-Ramos, 2007). Estos estudios sugieren la idea de un gobierno autoritario en el que las políticas son implementadas desde arriba y con escasa permeabilidad a la influencia de los actores.

Sin embargo, otros estudios muestran una visión más matizada respecto de la relación entre el gobierno y los actores socioeconómicos a propósito de la intervención económica estatal. Por un lado, Berrotarán (2003), quien trabajó sobre los consejos y comisiones en el periodo 1943-1946, subraya su función en tanto generadores de consensos previos para la formulación de políticas. Girbal-Blacha (2000) destaca el papel de los Consejos Regionales de Producción para lograr una mayor efectividad de la política agraria en el marco del "cambio de rumbo" de 1949. Elena (2011) señala la importancia que tuvo el proceso de incorporación de las demandas de la sociedad civil en la planificación estatal y estudia las políticas peronistas contra el agio y la especulación. Por otro lado, hay autores que rescatan experiencias de concertación social como el Congreso Nacional para la Productividad y el Bienestar Social de 1955, el cual promovió ciertos consensos entre el capital y el trabajo en torno al "lema" de la productividad o bien constituyó un "primer paso" hacia una política más amplia de concertación de clases (Cúneo, 1984; Giménez-Zapiola y Legui- 
zamón, 1988). Estos trabajos sugieren otra conceptualización de las políticas peronistas, en la que se observa la existencia de mecanismos de participación que redundaron en un diagnóstico más preciso de los problemas y en una mayor legitimidad de la planificación estatal, dada su capacidad para incorporar las demandas de distintos sectores. Así, se ha enfatizado que a partir del Segundo Plan Quinquenal (1953-1957) y de la constitución de la Confederación General Económica, se generaron mecanismos más efectivos de participación en el Estado y en la política económica (Brennan y Rougier, 2009; Rougier y Sowter, 2018).

Los argumentos sobre los que se sostiene la afirmación de que la burocracia peronista implementó las políticas de manera aislada y sin participación efectiva de los actores socioeconómicos, se basan en investigaciones empíricas que se centran fundamentalmente en el periodo 1946-1952. Por otro lado, tiende a minimizarse un componente que estuvo presente en documentos, planes, programas, leyes, discursos y decretos que definían el funcionamiento de organismos, desde el Consejo Nacional de Posguerra de 1944 hasta el Congreso Nacional de la Productividad y el Bienestar Social de 1955: los espacios institucionales de representación de los actores socioeconómicos. ${ }^{2}$ Otra cuestión es en qué medida estos organismos funcionaron y cómo lo hicieron, con qué efectos y consecuencias, lo cual no ha sido abordado de manera sistemática. En algún sentido, las caracterizaciones que abonan una concepción top down del proceso de la política económica peronista, suelen minimizar estos mecanismos de participación.

En consecuencia, en la bibliografía no se dispone, o son limitados, los estudios sistemáticos acerca de la historia de los organismos que canalizaron la participación de los actores socioeconómicos durante el primer peronismo. Es decir, aun aceptando la deficiente institucionalización de la participación de los actores en el Estado y en las políticas públicas -cuestión que, como argumentaremos, sólo puede sostenerse parcialmente para el periodo 1946-1952- no queda claro por qué ello fue así. Cuando hay referencias a algunas de estas experiencias, en general se la caracteriza como una pantomima política vacía o una experiencia inefectiva y fútil. Para lograr una caracterización más adecuada es preciso estudiar lo que sucedió en el interior de estos organismos, cuál fue su dinámica, quiénes participaron, qué se discutió y cuáles fueron sus resultados y su posible impacto sobre la política económica.

Teniendo en cuenta los aportes y vacíos de la bibliografía, el presente artículo se propone estudiar el proceso de relanzamiento de la cooperación económica a partir de 1949-1952, política que, a través de distintos consejos y comisiones, procuró vincular más sistemáticamente a los actores socioeconómicos con el proceso de la política económica. ${ }^{3}$ Con ello, se busca responder algunas cuestiones que todavía permanecen sin abordar. Por un lado, el funcionamiento de estos organismos, su organización, composición, jerarquía burocrática, objetivos y resultados esperados. Por otro lado, las discusiones tripartitas en su interior, las cuales transcurrían sobre bases más amplias que las discusiones de convenios colectivos, y que permiten ver qué estaba en juego para los actores. ¿Fueron efectivos los consejos y comisiones en canalizar la participación de los actores?, ¿qué rol cumplieron en el marco de la reorientación de la política económica?, ¿en qué medida habilitaron una mayor participación en la política económica?

${ }^{2}$ Estos espacios no sólo incluyen a los organismos específicos que institucionalizaron dicha participación, sino también a la representación que los distintos actores tuvieron garantizada en los directorios de los bancos estatales, juntas de producción, institutos y diversos organismos públicos. Esta última dimensión de la participación no es tratada en este trabajo.

${ }^{3}$ Por cooperación económica se entiende la vinculación institucional que los actores socioeconómicos mantienen a través de su presencia en los organismos estatales destinados a tal efecto. 
La metodología se basa en el análisis histórico, documental y de discurso, combinado con estudio de casos, desde donde se aborda una variedad de fuentes (primarias y secundarias) con un criterio que combina lo cronológico con lo temático con el objetivo de recuperar el proceso de las negociaciones tripartitas en estos consejos y comisiones. ${ }^{4}$ En una primera instancia, se abordan los aspectos principales de la política económica a partir de 1949 y el rol que debían cumplir los consejos y comisiones económicas. En segunda instancia, se analiza la dinámica de la cooperación económica a través de casos de estudio que permiten poner en juego la estrategia oficial: la Comisión de Precios y Salarios, la Comisión Económica Consultiva y el Congreso de la Productividad.

El trabajo se divide en tres partes. En la primera, se revisan los antecedentes 1946-1949 y se analiza el proceso de reformulación de la política económica a partir de 1949 y sus vicisitudes en el control de la inflación. En la segunda, se aborda la definitiva reorientación de la política económica y se estudia el caso de la Comisión Económica Consultiva y su rol en la "batalla" contra el agio y la especulación de 1953. En la tercera, se analiza el caso del Congreso de la Productividad de 1955 en tanto culminación de la política de la cooperación económica. En las conclusiones se hace un balance de los resultados del trabajo.

\section{EL DILEMA DISTRIBUCIÓN-CRECIMIENTO Y LA REFORMULACIÓN DE LA COOPERACIÓN ECONÓMICA}

El proyecto reformista y nacionalista que el gobierno peronista procuró implementar desde 1946 conllevó una redefinición de la intervención económica estatal y su relación con los actores socioeconómicos. Ya desde 1944, con el Consejo Nacional de Posguerra, quedó claro que para Perón y su círculo de colaboradores la política económica, industrialista, redistribucionista y en pro del mercado interno, debía contar con la institucionalización de la "colaboración" de empresarios y trabajadores (Sowter, 2014). Como las dos caras de una misma moneda, si la política económica promovía el "progreso", la cooperación económica aseguraría el "orden”.

En el periodo 1946-1949, la política económica se basó en la expansión de los salarios, el consumo, el empleo y el gasto público, lo que fue posible gracias a la doble redistribución del ingreso (de las actividades agropecuarias a las urbanas y, dentro de estas, del capital hacia el trabajo), en un contexto de altos precios internacionales (Rapoport, 2000; Rougier, 2012). Los empresarios también fueron beneficiados en la medida en que se les aseguró la protección del mercado interno y, sobre todo, un generoso flujo de crédito. Precisamente, este último fue el instrumento principal que promovió la "colaboración" entre el capital y el trabajo, lo cual se tradujo en el financiamiento estatal de los aumentos salariales. Así, el Banco de Crédito Industrial aumentó de 47.1 \% a 68.8 \% los créditos destinados al pago de salarios, retroactivos, vacaciones y aguinaldos entre 1946 y 1949 (Rougier, 2001, p. 80). En la medida en que la tasa de interés estuvo por debajo de la inflación, se operó un fuerte subsidio a las actividades industriales.

\footnotetext{
${ }^{4}$ El análisis de discurso permite abordar una dimensión importante en las interacciones entre los actores: los parámetros sobre los cuales se da el conflicto (político y económico) y las apelaciones/criterios de verdad a los que recurren en relación con el contexto. Particular atención recibe el "discurso público", entendido como un espacio de lucha de poder en donde los actores establecen batallas para determinar el sentido de las palabras y de los hechos sociales (Dijk, 2000). El estudio de casos nos permite abordar en profundidad unidades de observación (los consejos y comisiones) y así poner en discusión el problema de la participación de los actores en la política económica. La combinación de criterios temáticos y cronológicos - es decir, el análisis de la problemática de la cooperación económica en conjunto con la cronología de la política económica- permite abordar la complejidad del tema en cuestión, pues seguir un criterio en detrimento de otro llevaría a una exposición lineal y rígida que no nos permitiría dar cuenta de la relación entre la participación de los actores y las orientaciones de las políticas.
} 
Hasta la conformación de la Confederación General Económica (CGE) en 1952, los empresarios tuvieron una representación corporativa débil y una vinculación inorgánica con el gobierno, sustentada sobre bases individuales. ${ }^{5}$ Sin dudas, dicha debilidad fue funcional a las prioridades de construcción política del peronismo durante esos primeros años. En cambio, los sindicatos obtuvieron mejoras en los salarios y en las condiciones de trabajo a través de las negociaciones de convenios colectivos y del rol de las comisiones internas en las fábricas. Este proceso implicó una fuerte conflictividad que, por un lado, ayudó a consolidar la organización sindical y aumentar la participación de los trabajadores en el ingreso nacional y, por otro, permitió al gobierno un progresivo control del movimiento obrero a través de la Confederación General del Trabajo (CGT) (Doyon, 2006; James, 2010; Schiavi, 2013).

En este periodo, la función de la cooperación económica quedó a cargo de un organismo específico creado a tal efecto: el Consejo Económico y Social (CEs), dependiente del Consejo Económico Nacional (CEN) bajo el mando de Miguel Miranda, quien centralizó el manejo de la política económica. ${ }^{6}$ En un contexto signado por la expansión de la economía, la prioridad política de consolidar el apoyo de los trabajadores y la ausencia de una corporación empresaria reconocida oficialmente, la cooperación económica tuvo una dinámica unilateral y determinada por el gobierno. ${ }^{7}$ Sin embargo, estos factores cambiarían a partir de la crisis económica.

En efecto, a fines de 1948 se combinaron una serie de factores internos y externos que marcaron el agotamiento de una industrialización de bajo contenido tecnológico y fuertemente dependiente del ingreso de divisas. La caída de las reservas internacionales puso en jaque el modelo basado en la redistribución del ingreso y la expansión de la industria liviana. ${ }^{8}$ En una primera etapa, el gobierno aplicó políticas ortodoxas para detener la sangría de reservas y contener la creciente inflación, lo que generó una fuerte contracción económica. El escaso resultado de estas medidas, sus efectos recesivos y su alto costo político, llevaron a cambiar el equipo económico en enero de 1949, que quedó bajo la dirección de Alfredo Gómez Morales. Los dos principales problemas identificados eran la inflación y la escasez de divisas. La causa se reconocía en el crecimiento de la actividad industrial y del consumo, paralelo al desplazamiento de la producción agropecuaria. Las políticas sugeridas, priorizaban el aumento de la producción agropecuaria exportable, la racionalización de la industria y el aumento de la productividad laboral (Consejo Económico Nacional, 1949a, 1949b, 1951).

Pero las políticas finalmente implementadas respondieron a un fino cálculo político, que determinó tanto el timming como la profundidad en la reorientación de la política económica. La necesidad de impulsar las exportaciones y la inversión al tiempo que atender la inflación, implicó fuertes dilemas que se reflejaron en las marchas y contramarchas de las distintas medidas. Así, las restricciones al crédito implementadas a fines de 1948 fueron flexibilizadas en septiembre de

${ }^{5}$ En mayo de 1946 el gobierno de facto había decretado la intervención de la tradicional Unión Industrial Argentina (UIA). Al respecto, véanse Acuña (2014), Belini (2014) y Rougier y Sowter (2018).

${ }^{6}$ Miguel Miranda (1889-1953) era un empresario de posiciones nacionalistas y miembro de la UIA. En 1946 fue el artífice de la reforma financiera y ocupó la presidencia del Banco Central y luego del Consejo Económico Nacional, desde donde manejó la política económica. En enero de 1949 fue reemplazado por Alfredo Gómez Morales, de perfil más técnico y con una trayectoria ligada a la administración estatal. Al respecto, véase Stawski (2012).

${ }^{7}$ Respecto de la experiencia del ces, véase Sowter (2015).

${ }^{8}$ La implementación del Plan Marshall por Estados Unidos en 1947 excluyó la producción argentina e impactó a la baja en el precio de los alimentos a partir de 1948 (Rougier, 2012, pp. 109-122). Entre 1946 y 1949, las reservas internacionales cayeron de 1686.6 a 523.9 y el superávit comercial pasó de 499.9 a -138.8 (Rapoport, 2000, p. 421; Gerchunoff y Llach, 2003, p. 493). 
1949 (Banco Central de la República Argentina, 1952, p. 45). Lo mismo ocurrió con la política de subsidios a la producción agrícola y ganadera, que bajaron en 1949 y 1951 para incrementarse en 1950 y 1952 (Novick, 2004, p. 142).

Respecto de la política laboral, desde el Consejo Económico Nacional (CEN) se proponía, entre otras medidas, la celebración de convenios colectivos de no menos de dos años, evitar pagos retroactivos y que los aumentos salariales compensaran "estrictamente" la incremento en el costo de vida. A tono con lo que los empresarios reclamaban desde $1946,{ }^{9}$ se recomendaba implementar un régimen de estímulo que premiara la mayor productividad obrera y una política de precios “sobre bases económicas" (Consejo Económico Nacional, 1949b).

En contraposición, el gobierno procuró un mayor involucramiento del sector empresario. En mayo de 1950, Perón convocó a distintas cámaras y les adelantó que su intención era establecer un sistema "cada vez más libre, que no dependa del gobierno" sino del comercio, la industria y la producción. ${ }^{10}$ Con ello, el gobierno fue dejando en claro su nueva estrategia. Por un lado, buscaba que los propios empresarios enfrentaran las demandas obreras, pues el intercambio de opiniones permitiría "ir educando cada vez más a esos dirigentes" obreros. ${ }^{11}$ Por otro, se esperaba la "colaboración" empresaria para efectivizar los precios oficiales y "vigilar" el ciclo económico, denunciando a los "especuladores".

Sin embargo, el gobierno no contaba con dicha colaboración debido a una razón muy básica: no existía una organización reconocida y que representase a todo el empresariado nacional. La apuesta oficial era que la futura central pudiera negociar con los trabajadores "las condiciones de sueldos, salarios, etc., mientras por su parte discuten con el Estado y con los consumidores precios, etc.", tal como Perón mencionó en julio de 1950 en la Bolsa de Comercio de Buenos Aires (Perón, 1997, vol. 12.2, p. 325). Es importante destacar que el gobierno preveía la conformación de dicha organización en forma progresiva.

En este mismo año, la economía parecía estabilizarse. La inflación disminuyó y la balanza comercial arrojó un saldo positivo, lo que permitió recomponer parte de las reservas de oro y divisas. ${ }^{12}$ Pero el optimismo oficial no se mantuvo en 1951, cuando una gran sequía arruinó la campaña 1951-1952, lo cual afectó la balanza comercial, exacerbó la escasez de divisas y atizó la inflación.

De esta manera, el problema de la escalada de precios y salarios pasó a ocupar el centro de las preocupaciones oficiales. En la medida que las restricciones crediticias y el recorte de subsidios limitaron la capacidad para otorgar aumentos salariales, las empresas trasladaron sistemáticamente el aumento de costos a los precios. En consecuencia, el equilibrio entre capital y trabajo que el peronismo proponía como eje de la gobernabilidad económica se fue quebrando. Entre 1949 y 1951 la inflación promedió 31.1 \% anual, lo cual provocó una caída de casi 20 puntos en los salarios

${ }^{9}$ Estas medidas venían siendo reclamadas por los empresarios en el cEs (Sowter, 2015).

${ }^{10}$ A falta de una central empresaria, la reunión estuvo compuesta por representantes de: Cámara de Grandes Tiendas y Anexos, Cámara de Industrias y Comercios, Cámara Industrial Argentina de Confeccionistas, Federación de Entidades de Comercios Minoristas y la Cámara de Comerciantes Mayoristas (La Nación, 13 de mayo de 1950).

${ }^{11}$ Perón (1997, vol. 12.1, pp. 198-199). Este pasaje no estaba reproducido en la nota de La Nación porque fue a puertas cerradas.

${ }^{12}$ Respecto de 1949, en 1950 la inflación cayó de 31 a $25.6 \%$ anual, el balance comercial pasó de - 138.8 a 122.2 y las reservas aumentaron de 523.9 a 690.5 millones de dólares corrientes (Rapoport, 2000, p. 421; Gerchunoff y Llach, 2003, pp. 493 y 496). 
reales (Villarruel, 1988, p. 426). Paralelamente, el gobierno comenzó a ejercer, a través de la cGT, un mayor control sobre el movimiento obrero, intervino sindicatos y limitó el recurso a huelga (Doyon, 2006).

A partir de 1949 se fortalecieron los controles de precios que se aplicaban desde 1946: se aplicaron topes máximos, límites a los márgenes de ganancias, precios máximos en artículos básicos y estacionales y control de la producción, ventas y existencias. Sin embargo, estas medidas se mostraron insuficientes para combatir la inflación, que desde 1948 comenzó a superar el promedio mundial. Es en este contexto en el que la cooperación económica adquiriría una mayor relevancia, pues en la medida en que la "batalla" contra los precios no mostró los resultados esperados, el gobierno consideró necesario alinear en mayor medida el comportamiento de los actores socioeconómicos con los objetivos de la política económica.

En el marco de la reforma burocrática y administrativa de 1949, se creó en agosto la Comisión Nacional de Cooperación Económica (CNCE) como organismo consultivo del CEN, la cual sustituía “con ventajas" al anterior Consejo Económico y Social. La política económica ahora debía trazarse "sobre la base de coordinar en mayor medida la colaboración" con los actores socioeconómicos (Decreto núm 18.814/49, énfasis mío). Los consumidores fueron incluidos por primera vez. En el acto de constitución de la CNCE, en febrero de 1950, Perón consideró que el anterior Consejo Económico y Social no había podido ser muy efectivo "porque en las épocas de reformas hay que andar rápidamente. Las reformas que nosotros tuvimos que realizar no se prestaban para hacer muchas consultas" (Perón, 1950, p. 14). El reconocimiento auguraba vientos de cambio, pues "si ha sido importante la colaboración que pudieron prestarnos las fuerzas económicas y sociales durante la etapa de reforma, va a ser mucho más importante la que nos puedan prestar en el periodo de estabilización" (Perón, 1950, p. 15).

La integración del cuerpo permanente era muy heterogénea, y los veinte representantes que la conformaban no facilitó su funcionamiento. Sin embargo, fue la inexistencia de una organización representativa del empresariado lo que debilitó la CNCE. Por momentos, la cooperación económica aparecía como el reemplazo funcional de una central empresaria unificada. En el discurso al Congreso en mayo de 1951 Perón dijo que "atendiendo a la necesidad imperiosa de una colaboración directa de los productores, hemos debido organizar nosotros mismos esa cooperación. Así hemos creado, por ejemplo, la Comisión Nacional de Cooperación Económica y el Instituto Ganadero” (Perón, 1997, vol. 14.1, p. 269).

Hacia mediados de 1951, cuando quedó claro que la crisis ya no podía seguir siendo "manejada”, el gobierno diseñó una estrategia política con el objetivo de reorientar definitivamente la política económica. En la medida en que los controles de precios y el crédito habían mostrado límites para sostener el "equilibrio" entre precios y salarios, el gobierno puso en marcha una estrategia que culminaría en el Plan de Emergencia Económica de 1952 y que tenía como eje un acuerdo de precios y salarios a través del cual se buscaría quebrar la puja distributiva. Pero para ello, primero se necesitaba una representación empresaria, factor que catalizó los esfuerzos oficiales por contar con una organización representativa de todo el capital nacional. ${ }^{13}$ Así, en diciembre de 1951 se convocó a empresarios de todo el país en la Facultad de Derecho en donde se establecieron tres confederaciones nacionales (industria, comercio y producción), base sobre la cual se creó la CGE al año siguiente.

${ }^{13}$ Es de destacar que en los estudios sobre el empresariado durante el peronismo se ha soslayado el peso que tuvo la política de la cooperación económica en el origen de la CGE. 
El 24 de diciembre, Perón y los miembros del cEN recibieron en el despacho presidencial a los secretarios de la CGT y a "los presidentes y secretarios de la Confederación de la Producción, Industria y Comercio" (La Nación, 16 de diciembre de 1951). ${ }^{14}$ En esta reunión, Perón planteó el temario sobre el cual los actores debían expedirse: $a$ ) acordar la relación entre salarios y precios a septiembre de 1949, año a partir del cual se consideraba el quiebre del equilibrio; $b$ ) la relación “actual" de salarios y precios; $c$ ) la forma de restablecer la relación primitiva y $d$ ) cómo mantener ese nuevo equilibrio. La subcomisión para el "Equilibrio de Precios y Salarios" que sesionó en el CEN debía culminar las negociaciones para el 24 de enero y elevar un informe común al presidente. Sin embargo, las seis reuniones planeadas fueron insuficientes y los encuentros tuvieron que extenderse hasta el 22 de febrero, requiriéndose de seis reuniones más; pese a lo cual el informe común no se produjo y fue el propio Perón quien debió establecer los nuevos niveles salariales, junto con un congelamiento de precios.

El problema definido por el gobierno - lograr aumentos de salarios sin traslado a preciosconstituía una interpelación directa a la "responsabilidad" empresaria. Pero los actores llegaron a la mesa con posiciones distintas sobre cuál era el problema por resolverse, lo que explica la dilatación de las reuniones. Respaldada por el gobierno, la cGT buscó recuperar el terreno perdido en la distribución del ingreso. De hecho, el pedido oficial de recuperar el equilibrio de septiembre de 1949 implicaba sostener el mayor nivel de participación asalariada en el ingreso. ${ }^{15}$ En cambio, para la delegación empresaria la inflación era la manifestación de un problema mayor, ubicado en la esfera de la producción, por lo que buscó romper el corsé con el que el gobierno había enmarcado el objetivo de las reuniones.

$\mathrm{El}$ argumento de los empresarios era que los aumentos salariales debían basarse en un incremento de la productividad obrera, pues de lo contrario se presionaría sobre los precios. Juzgaban que el principal problema era la caída del rendimiento laboral, algo que vinculaban a la pérdida de disciplina, al ausentismo y al trabajo a desgano. El cuadro se completaba con el aumento de los costos de producción, no sólo de las materias primas, electricidad y transporte; sino también de salarios y beneficios laborales. A esto se sumaban los controles de precios y restricción de utilidades, que habían comprimido el margen de ganancias y que incentivaba el mercado negro. También reclamaron por las restricciones al crédito y a las importaciones, que dificultaban la renovación de equipos y disponibilidad de materias primas. Pero sin dudas, el principal reclamo era, en palabras de Aquiles Merlini, "la vuelta" a la producción obrera "normal", para que "produzcan dentro de la posibilidad de lo que se producía hace 5 o 6 años" (Consejo Económico Nacional, 1952, vol. 2, p. 11).

En cambio, para los delegados de la cGT el problema era la pérdida del poder adquisitivo a causa de los aumentos de precios, por lo que la solución propuesta consistía en un aumento general de salarios y el compromiso de que el aumento saliese de las ganancias empresarias y no fuese trasladado a precios. Tampoco admitían vincular la discusión a un tema mayor como el régimen de relaciones laborales. De todas formas, desmentían que el rendimiento fuese un problema, pero que en todo caso podría aumentarse habilitando la participación obrera en las ganancias.

${ }^{14}$ En las distintas fuentes consultadas la comitiva empresaria era denominada de diversas maneras, lo cual muestra que la central estaba en proceso de formación y confirma la urgencia del gobierno por contar con ella.

${ }^{15}$ En efecto, Villarruel (1988, p. 426) estima que en 1949 los salarios reales alcanzaron su pico: $172.7(1945=100)$. 
Ante el fracaso de las negociaciones, el gobierno resolvió, por un lado, homologar los aumentos de precios "justificados" y rebajar y congelar los "no justificados" y, por otro lado, un fuerte aumento salarial de 40 a $80 \%$. En cambio, los problemas relativos a la producción serían resueltos a través de la cooperación económica: Perón anunció que se encomendaría al cEN, la Confederación Económica y la CGT "un plan de acción común destinado a buscar la solución mediata y de fondo" (La Nación, 13 de febrero de 1952). Es decir, la introducción de posibles modificaciones en el régimen de relaciones laborales no sería producto de una decisión del gobierno, sino una política concertada entre la CGE y la CGT.

Los diálogos con los empresarios muestran que, más allá del discurso de Perón, la realidad era que "la contrapartida a la fijación de los salarios es la contención de los precios", tal como les aclaró Gómez Morales (CEN, 1952, v. 9, p. 13). En privado, el ministro les aseguró a los empresarios que la congelación de precios era una medida "transitoria” y que el CEN estudiaría los casos individuales, aportando crédito a las empresas que no pudiesen afrontar los aumentos (CEN, 1952, v. 9, pp. 31 y 49). Aunque las utilidades se estrechaban en productos básicos, se ampliaban en los demás artículos. El apoyo empresario quedó sellado con la promesa oficial de aumentar el crédito y garantizar su participación en las decisiones. La fórmula fue resumida por Gómez Morales: "que no saliera ningún precio sin conocimiento de las partes interesadas" (CEN, 1952, vol. 9, p. 47).

Las discusiones que se dieron en torno a la creación de la Comisión Nacional de Precios y Salarios iluminan con mayor precisión el sentido que cobró el proceso de reformulación de la cooperación económica. A propósito de la discusión de la presidencia de la Comisión, se generó un contrapunto entre el gobierno y la CGT. En primer lugar, por el rol que debía cumplir el Estado. Para la central obrera la presidencia debía quedar en manos del poder ejecutivo, quien debía "allanar las interferencias o situaciones producidas entre el capital y el trabajo" y bajar las directivas y "orientaciones" (CEN, 1952, vol. 9, pp. 35-36). Es decir, esperaban una continuidad en la forma de intervención del Estado en las relaciones laborales. En contraposición, el gobierno buscaba reformular el rol del Estado. El presidente del CEN, Ramón Cereijo, pidió que "no esté siempre el Estado como juez y parte" y que se esperaba que los actores propusieran "medidas concretas de gobierno" (CEN, 1952, vol. 9, p. 34). Y agregó: "no queremos dar a la Comisión un sello estatal" por lo que "el Estado no debe votar, sino que debe intervenir después para ejecutar las medidas que ustedes propongan” (CEN, 1952, vol. 9, pp. 44-45).

En segundo lugar, el contrapunto muestra que el gobierno buscaba correrse de las cuestiones más espinosas que hacían a las relaciones entre empresarios y trabajadores, lo cual llevaba a fortalecer la cooperación económica. En este sentido, Cereijo enfatizó que, a despecho de las críticas de la CGT sobre la falta de facultades de la Comisión Nacional de Cooperación Económica de 1949, ahora se entraba en una nueva etapa pues "las facultades que el decreto da a la Comisión son concretas" (CEN, 1952, vol. 11, pp. 47 y 51).

A partir de entonces, quedaba redefinido el rol del Estado, que para el gobierno pasaba a constituirse en un espacio donde los actores socioeconómicos debían ponerse de acuerdo y elevar propuestas de políticas que luego el gobierno se encargaba de ejecutar. En palabras de Cereijo, el gobierno esperaba de los actores "medidas concretas para facilitar la acción del gobierno", pues "el gobierno no quiere adoptar medidas que solucionen problemas que se crean las mismas partes [...]. Queremos una colaboración efectiva y real” (CEN, 1952, vol. 4, pp. 25-26). 


\section{LA “COMUNidAd ORGANIZADA” EN AGCiÓN: LA COOPERAGión ECONÓMICA PUESTA A PRUEBA}

A partir de la experiencia de la Comisión de Precios y Salarios, el gobierno entendió que resultaba imprescindible un mayor involucramiento de los empresarios con los objetivos de la política económica. Luego de lanzar el Plan de Emergencia Económica de 1952, la cooperación económica se volvió una herramienta importante para el control de precios y salarios. Ello incentivó la definitiva conformación de la "pata" empresaria en la "Comunidad Organizada". Sin embargo, el proceso de armado de la CGE se dilató desde fines de 1951 hasta mediados de 1953, lo cual muestra que la entidad no fue enteramente obra del gobierno peronista (Brennan y Rougier, 2009). Hacia fines de 1952 el gobierno pudo contar con una central empresaria y en agosto de 1953 José Ber Gelbard fue ungido su presidente. A fines de ese mismo mes se dictó un decreto que terminó de diluir definitivamente a la Unión Industrial Argentina, cuyos exmiembros, en conjunto con las tradicionales Sociedad Rural Argentina y Bolsa de Comercio de Buenos Aires, pasaron a formar parte de la nueva central. Finalmente, en diciembre el poder ejecutivo remitió la Ley de Asociaciones Profesionales de Empleadores, similar a la que regía para la CGT, que establecía la existencia de una organización patronal por sector industrial para que pudiese negociar con los trabajadores.

Una vez conformada la CGE el gobierno pudo relanzar la cooperación económica sobre bases más sólidas. Ya desde el armado del Segundo Plan Quinquenal, con la campaña "Perón quiere saber lo que su pueblo necesita" de 1951, se perfiló esta estrategia que buscaba una mayor participación de los individuos y de las organizaciones en la planificación y en las políticas. ${ }^{16}$ El Segundo Plan Quinquenal establecía en uno de sus primeros "Objetivos Fundamentales" que el Estado buscaría "disponer del asesoramiento permanente de representantes de las entidades de empresarios y trabajadores" (Presidencia de la Nación, 1953, pp. 39-42).

El instrumento fue la Comisión Económica Consultiva (CEC). Creada en enero de 1953, se diferenció de los organismos anteriores, el cEs y la CNCE, en varios aspectos. ${ }^{17}$ Primero, porque estipulaba la regularidad de su funcionamiento: se reuniría "por lo menos" una vez al mes y actuaría "en regular contacto" con presidencia y los ministerios. Segundo, institucionalizaba la participación de la CGE y la CGT, no sólo para asesorar (función consultiva) sino también para proponer medidas (función participativa). Y, tercero, dispuso de una estructura estable que reflejaba la dinámica del juego corporativo en el plano nacional. Estaba integrada por doce miembros, que gozaron de estabilidad: cuatro por cada sector representado, Estado, CGT y CGE, designados por el poder ejecutivo, estos últimos a propuesta de las entidades. A diferencia de anteriores organismos, su integración quedó constituida a los dos meses de creada, lo cual refleja la necesidad de su funcionamiento. ${ }^{18}$

Su estructura disponía de siete comisiones: Nivel de Vida, Comercio Interior, Comercio Exterior, Industrias Extractivas, Industrias Agropecuarias; Industrias de Transformación y Vivienda, que trabajarían en los respectivos ministerios del equipo económico. La mecánica de funcionamiento era similar a la de la Comisión de Precios y Salarios: el temario era determinado por el

${ }^{16}$ Esta campaña buscó despertar la mística y unir los esfuerzos de la población con los objetivos gubernamentales. Lanzada en diciembre de 1951 y organizada por el Ministerio de Asuntos Técnicos, se recibieron sugerencias de individuos y organizaciones para la formulación del Segundo Plan Quinquenal (Archivo General de la Nación, fondo documental Secretaría de Asuntos Técnicos, leg. 647).

${ }^{17}$ Decreto de creación núm. 1.516/53 y Decreto de Reglamentación núm. 8.277/53. La cEc reemplazó a la CNCE.

${ }^{18}$ Ya el 12 de marzo el decreto núm. 3.993 definió sus miembros titulares. Por la cGT: Eduardo Vuletich, Héctor Hugo Pietro, Valentín Fernández y Luis Cabrera. Por la cGe: Gastón Solari, Eduardo Carlos Verardo, Francisco Muro y Ángel Borghi. Los miembros de la CGT y la CGE duraban un año en sus cargos, con excepción de sus secretarios generales, que permanecerían en tanto estuviesen al frente de sus respectivas confederaciones. 
gobierno y las sesiones podían finalizar en acuerdos o bien presentar despachos por separado. También podían llamar a distintos representantes empresarios para testimoniar sobre sus respectivos sectores. Toda la masa de información generada a partir de las deliberaciones tendría "invariablemente carácter reservadas”, lo cual muestra que su accionar no sólo operaba en el discurso público, sino que además procuraba propuestas concretas de política económica.

Dentro de las Comisiones, la más importante fue la de Nivel de Vida, que operó bajo la órbita de Gómez Morales. En cuanto a sus funciones, se establecían dos grandes tareas: $a$ ) el estudio permanente de los niveles de vida en las distintas zonas y sectores económicos del país, en temas como consumos, presupuestos familiares, precios, salarios, salario real y ahorro; $b$ ) propuestas de medidas concretas que pudieran asegurar "en todo el país el equilibrio entre precios y salarios". De esta manera, el gobierno podría contar con una masa de información detallada acerca del impacto social de la política económica.

El Segundo Plan Quinquenal (1953-1958) cristalizó sobre bases permanentes la reorientación de la política económica que se había ensayado desde 1949. Ahora se buscaba impulsar de forma consistente la producción agropecuaria exportable, la inversión extranjera y las ramas pesadas de la industria como la siderurgia, química, aluminio, mecánica y eléctrica. En febrero de 1953, en una serie de conferencias radiales, Perón consideró que "las distintas medidas de carácter económico" se tomarían "de común acuerdo con la Comisión Económica Consultiva” y anunció que "la planificación en la distribución de divisas para las necesidades industriales será realizada con el asesoramiento de la Comisión Económica Consultiva” (Perón, 2000, vol. 17.2, p. 943).

En la práctica, el gobierno buscó que la cooperación económica se enfocara en el mantenimiento del equilibrio de precios y salarios. El margen de maniobra de la política económica resultaba sumamente estrecho, y estaba marcado por el dilema de cuidar el poder adquisitivo del salario vs. incentivar la producción concediendo precios remunerativos. A lo largo de 1952, el gobierno penduló entre hacer valer el control de precios o flexibilizarlo de modo que evitara mayores quebrantos en el comercio, la industria y el campo. ${ }^{19} \mathrm{El}$ enfoque oficial fue pragmático pero oscilante. En este sentido, se pueden distinguir dos etapas. La primera, entre marzo y noviembre de 1952, está marcada por la flexibilización en el control de precios. A tono con lo que habían reclamado los empresarios en la Comisión de Precios y Salarios, hubo una mayor liberalidad con el objetivo de incentivar el aumento de la producción.

Pero cuando la inflación trepó a 38.8 \% en 1952, el pico más alto en todo el periodo peronista, se encendieron las alarmas. En enero de 1953 el poder ejecutivo recibió el informe de la Comisión Nacional de Precios y Salarios sobre el nivel de vida del año 1952, que mostraba un aumento en el costo de vida de 9.9 \% y sugería un aumento salarial en igual proporción (Comisión Nacional de Precios y Salarios, 1952). El equipo económico desestimó esta propuesta pues temía el traslado a precios. En cambio, se inclinó por acentuar los controles y limitar la política de liberación de precios máximos.

Hacia marzo de 1953 la inquietud fue creciendo en el campo laboral, pues entre 1949 y 1952 los salarios habían caído 35.5 puntos (Villarruel, 1988, p. 426). Luego de formulado el Segundo Plan Quinquenal y de creada la Comisión Económica Consultiva, se abrió una segunda etapa, en la que el gobierno aplicó una política más frontal contra el aumento de precios, pero en la que, a diferencia del periodo 1946-1949, la cooperación económica jugaría un papel importante. El 1 de abril, Perón convocó a la prensa y advirtió: "esto que fue un litigio inicial entre consumidores

${ }^{19} \mathrm{Al}$ respecto, véase Mainwaring (1986). 
y proveedores ha pasado a ser un problema de Estado para mí en este momento" (La Nación, 2 de abril de 1953). Sostuvo que la cEc estudiaría "ecuánimemente" la situación y que a partir de ahora "vamos a declararnos, tanto el gobierno como la Comisión Consultiva Económica y la Comisión de Precios y Salarios, en sesión permanente hasta que solucionemos el problema” (Perón, 2000, vol. 17.1, pp. 162-163).

Luego de estas intervenciones en el debate público, tuvo lugar una sesión de la cec. ${ }^{20}$ Perón marcó las directivas bajo las cuales se encararía la acción oficial y expresó su preocupación por la introducción de "elementos políticos". El objetivo era, nuevamente, recuperar el equilibrio de precios y salarios, haciendo respetar el acuerdo de marzo de 1952. Un punto destacado en privado fue la necesidad de comenzar a modificar la política de austeridad. Perón señaló que "[h]ay deudas del Estado que están impagas y que también inciden porque eso va retirando de la circulación una gran cantidad de dinero. [...] Hay que reactivar el país. [...] Estamos en un plan de equilibramiento y de economía; pero esa economía no debe llegar a tal punto que empecemos a morirnos de hambre" (Perón, 2000, vol. 17.1, pp. 167-168).

La estrategia del gobierno quedaba confirmada: Perón pidió a la CEC "que se expida rápidamente con las soluciones, que nos diga qué hay que hacer" y que a "toda esa tarea" se le dé una "amplia publicidad, porque el pueblo quiere saber qué es lo que se está haciendo” (Perón, 2000, v. 17.1, p. 169).

El problema de fondo era que el acuerdo de precios distaba de arrojar los resultados esperados. Sin embargo, lejos de renunciar a esta herramienta, el gobierno se proponía hacerla más efectiva. Gómez Morales, reacio a implementar una devaluación general y a subir los salarios en la misma proporción que los precios, planteó que el problema era que se había dejado demasiado margen en la libertad de precios, y propuso "volver al procedimiento ya conocido de establecer precios justos, sobre todo en los productos alimenticios [...]. Tenemos que eliminar ese escepticismo reinante de que resultamos ineficientes para hacerlos cumplir". Ratificando esta línea, Perón amenazó: "yo voy a poner el Ejército, si es necesario. Pondré un centinela en cada boliche. iLo voy a hacer cumplir a culatazos! iY van a tener que cumplir!" (Perón, 2000, v. 17.1, p. 171).

El testimonio de la GGT reveló ineficiencias en la política de cooperación. Luis Cabrera reprochó que no disponían de la información sobre la liberación o fijación de precios y reclamó no recibir "como cosa hecha una planilla de precios para que nosotros, lisa y llanamente, (la) aceptemos" (Perón, 2000, v. 17.1, p. 170). Gómez Morales prometió que "todos esos inconvenientes no se van a repetir", lo cual muestra la necesidad de lograr contar con una colaboración más efectiva.

En los días posteriores, la CEC mantuvo reuniones maratónicas hasta llegar a un acuerdo. El temario revela objetivos más modestos que los de la subcomisión de Precios y Salarios de 1952, puesto que se centró en evitar el encarecimiento de los productos básicos. El gobierno trazó los puntos a tratar: $a$ ) "precios justos" para artículos que integran el presupuesto familiar; $b$ ) medidas para que se respeten dichos precios; $c$ ) en caso de desequilibrio entre precios y salarios, proponer medidas concretas para reestablecerlo; $d$ ) medidas para mantener dicho equilibrio.

Las negociaciones repitieron en parte una dinámica ya conocida. La cGT culpaba a los empresarios por haber roto el equilibrio y denunció que en todos los casos en que se habían liberado los precios, estos aumentaron, y citó casos: aguas gaseosas, vinos comunes, artículos de tocador y

${ }^{20}$ Las sesiones fueron presididas por Alfredo Gómez Morales (ministro de Asuntos Económicos) y participaron los ministros de Agricultura y Ganadería (Carlos A. Hogan), Industria y Comercio (Rafael F. Amundarain), Comercio Exterior (Antonio Cafiero), Finanzas (Miguel Revestido) y Hacienda (Pedro Bonanni). 
fideos. Más grave aún, ello ocurrió en artículos sensibles como pan, carne, aceites, harinas y azúcar, "artículos que representan más del $40 \%$ de la canasta familiar". Su propuesta era volver "al régimen de congelación de precios sobre las bases de los que existían en 1952" (La Nación, 4 de abril de 1953). La CGE, en cambio, buscaba morigerar los controles de precios porque "desalentaba las actividades económicas" en un contexto ya desfavorable para las empresas en el que "no registraban ganancias" y en el que "luchan" para afrontar "deudas con instituciones bancarias, el fisco, las cajas de jubilaciones y los proveedores" (La Nación, 4 de abril de 1953).

Gómez Morales ensayó una especie de laudo, reconociendo que había algunos incrementos de precios "justificados", pero que en el caso del pan y de la carne se presentará "un proyecto de fijación de precio definitivo". En el resto de los productos esenciales, se fijaría un precio "justo" en base a un cálculo de costos y de una ganancia "razonable". El jefe del equipo económico se mostraba confiado en que bajarían los precios debido a que serían renovados los stocks de importación y que "el mercado mundial estaba en baja" (La Nación, 2 de abril de 1953). Por su parte, Amundarain, titular de Industria y Comercio, explicitó que se habían liberado los precios de ciertos alimentos debido a que se pensó "en la reactivación económica que esa decisión promovía”. Pero sostuvo que el problema podría resolverse ampliando la participación de los actores en la fijación de los precios: "la comisión que se designara para cada artículo podría decir si el Ministerio ha seguido una política sana o equivocada al liberar esos precios" (La Nación, 2 de abril de 1953).

Si bien el día 6 la Comisión de Nivel de Vida presentó dos despachos por separado, el 7 de abril se llegó a un acuerdo en el que la CGE aceptaba "la solución propuesta, en el entendimiento de que los precios a fijar comprenden un margen razonable de utilidad" (La Nación, 8 de abril de 1953). Gómez Morales anunció la fijación de precios máximos para distintos "artículos que gravitan sobre el encarecimiento de la vida" (La Nación, 8 de abril de 1953). Una vez que la CEC hizo público el acuerdo, el gobierno intensificó su actividad contra el aumento de precios "injustificado". La estrategia política quedaba definida: a través de la cooperación económica los actores acordaban precios y salarios, de manera que dichos niveles quedaban legitimados. Luego, la implementación y el enforcement del acuerdo quedaba en manos de toda la "Comunidad Organizada" bajo el liderazgo personal de Perón.

El 8 de abril el jefe de Estado pronunció un discurso desde la Casa de Gobierno y transmitido a todo el país por radio, donde anunció durante 45 minutos las medidas que procuraban "poner término a las maniobras agiotistas y especulativas". En este sentido, solicitó a toda la población, “a cada consumidor, a cada ciudadano, a cada peronista”, su involucramiento activo en la campaña (La Nación, 9 de abril de 1953). En los días siguientes, tuvo lugar una intensa acción estatal y mediática dirigida a hacer respetar los precios oficiales y normalizar el abastecimiento de alimentos en la Capital Federal. Los medios difundían a diario los precios oficiales y las listas de comercios y mataderos clandestinos que eran clausurados. Incluso se publicaban los nombres de consignatarios y propietarios "agiotistas" de establecimientos del rubro carne, aves y verduras que eran detenidos y "remitidos" a la cárcel de Villa Devoto. La Municipalidad de la Capital Federal aplicaba "nuevas sanciones, disponiéndose la exclusión e inhabilitación definitiva” de los concesionarios de carne que "especulaban" (La Nación, 9 de abril de 1953).

Finalmente, y de manera ritual, el 14 de abril culminó toda la campaña con un paro y una movilización popular a Plaza de Mayo, organizada por la cGT. Se adhirieron entidades tan disímiles como las Fuerzas Armadas, la Corte Suprema, la Bolsa de Comercio, farmacias, periodistas, etc. 
En el discurso oficial, la unidad de la "Comunidad Organizada" era un hecho y Perón continuó apelando a la solidaridad para lograr la efectividad en la política de precios (La Nación, 15 de abril de 1953).

$\mathrm{Al}$ mes siguiente, los ministros de Asuntos Técnicos y Asuntos Económicos dieron a conocer en conferencia de prensa la "Situación Económica Argentina". Luego de atribuir la inflación a los saboteadores y enfatizar el carácter "político" de la misma, Gómez Morales destacó el "éxito" de la acción emprendida: "Las estadísticas [...] demuestran que, al adoptarse aquellas medidas contra el alza de los precios, el costo de la vida fue rebajado al nivel de abril de 1952. Los precios de la alimentación han descendido 70 puntos por esta acción en una campaña de veinte días. [...] La situación se ha normalizado totalmente y, prácticamente, estamos en los mismos niveles de 1952" (Gómez-Morales, 1953, p. 239).

Si bien para el gobierno la campaña en defensa del salario y "la batalla" de los precios había sido exitosa, tenía igualmente claro que la "guerra" no estaba ganada. Para ello se requería de la implementación de políticas "mediatas", que los empresarios ya habían reclamado en la Comisión de Precios y Salarios de 1952. Así, el problema de la productividad pasaría a ocupar el centro de la agenda de la cooperación económica.

\section{DE LO INMEDIATO A LO MEDIATO, DE PRECIOS Y SALARIOS A LA PRODUCTIVIDAD}

El año 1953 finalizó con $4 \%$ de inflación y 1954 con $3.7 \%$, el índice más bajo de todo el periodo peronista. Ello permitió que luego de la renegociación de los convenios colectivos de 1954, los salarios reales aumentaran 20 puntos respecto de 1952, aunque quince puntos por debajo del pico de 1949. El acuerdo de precios y salarios y la intensa acción oficial fueron fundamentales para lograr el "equilibrio". La colaboración de los sindicatos para el mantenimiento de la tregua salarial se logró a través de una fuerte presión sobre la CGT. También resultó clave la ampliación de subsidios a los servicios públicos y al consumo de carne, pan y otros productos agrícolas, que aumentaron de menos de $20 \%$ del gasto corriente de 1952 a $30 \%$ en 1955 (Mallon y Sourrouille, 1973 , p. 205). El equilibrio general de la economía se vio reforzado por el saldo positivo de la balanza comercial a partir de 1953.

Una vez superada la crisis, el gobierno se propuso enfrentar algunos de los principales problemas ya identificados en los documentos del CEN de 1949 y 1951, entre los que se mencionaba aumentar la productividad industrial. Pero atar salarios a productividad implicaba introducir fuertes modificaciones en el modelo vigente de relaciones laborales, lo cual implicaba un fuerte costo político. Es en este marco en donde la cooperación económica se reforzó como una estrategia que buscó dejar en manos de los actores la discusión sobre la problemática de la productividad.

Con la conformación de la CGE, los empresarios ganaron espacio simbólico y material dentro de la "Comunidad Organizada", donde pudieron plantear con claridad su agenda en el discurso público. Con la organización del Congreso General de la Industria (CGI) en 1953 y el Primer Congreso de Organización y Relaciones del Trabajo (CORT) en 1954, articularon públicamente sus demandas: reposición del crédito, renovación de maquinarias, equipos y repuestos, importación de materias primas para la industria, privatizaciones y retirada del Estado (al cual acusaban de "competencia desleal") y extensión del sistema de transportes que afectaba especialmente a las economías regionales. Pero sin dudas el principal reclamo pasaba por la modificación del modelo 
vigente de relaciones laborales. Esta es la problemática que se condensaba en la cuestión de la productividad, y que los empresarios buscaban resolver principalmente atando los aumentos salariales a los incrementos en la productividad.

La estrategia del gobierno consistió en ampliar el espacio de los empresarios en la "Comunidad Organizada” y luego fortalecer la cooperación económica como lugar privilegiado para que los actores "acordaran" las medidas. Por ello, una vez constituida la CGE a fines de 1953, el gobierno otorgó a los empresarios una participación inédita dentro del Estado y el gobierno, lo cual les permitió impulsar su agenda, que ahora coincidía con la oficial. Junto con la liberalización y privatización de la economía se llamaba a una mayor participación en la acción de gobierno. A fines de 1952 Perón prometió que no tomaría "ninguna medida sin consultar antes a su organización: si nos equivocamos, seremos culpables todos y no solamente yo" (Perón, 1997, vol. 15, p. 416).

La invitación era amplia. "El Estado tiene en la actualidad un sinnúmero de empresas que, en cualquier momento, pueden ser entregadas a las empresas privadas" (Perón, 2002, vol. 18.1, p. 294). A fines de 1954, Perón mostró hasta qué punto estaba comprometido en ampliar la participación empresaria en la política económica: "Nosotros haremos el proteccionismo que la cGE nos aconseje (...), también queremos que sea la GGE la que distribuya las divisas para reequipamiento, de acuerdo a las necesidades" (Perón, 2002, v. 18.2, p. 615). Como contrapartida, se esperaba que la central también asumiese "la responsabilidad de las decisiones gubernamentales", lo cual abona la existencia de una estrategia para distribuir la responsabilidad por los resultados de la nueva política económica: "nuestro interés no está solamente en recibir esa colaboración, sino en complicarlos a todos ustedes con nosotros, así cuando protestamos, protestaremos todos" (Perón, 2002, vol. 18.2, p. 616).

También respecto del crédito -instrumento privilegiado del peronismo para reorganizar la economía- el gobierno satisfizo demandas de larga data del empresariado del interior. Luego de convocar a la CGE a participar en la creación de los consejos regionales, les anunció que en la distribución del crédito "debe intervenir la CGE, y así después nos echaremos mutuamente la culpa" respecto de los resultados de dicha política (Perón, 2002, vol. 18.2, p. 616). ${ }^{21}$ El Ministro de Finanzas, Miguel Revestido, confirmó esta orientación en el Congreso de la Confederación de la Industria de julio de 1954, donde sostuvo que su cartera "orienta sus organismos técnicos hacia un atento y permanente contacto con las organizaciones económicas, cuyas opiniones se ponderan detenidamente antes de la resolución definitiva” (Revestido, 1954, p. 11).

En junio de 1954, en la primera convención de las federaciones económicas de las provincias, Gómez Morales resumió la estrategia de maximizar la participación empresaria "en la función de gobierno” y citó al propio Gelbard, quien participaba de las reuniones semanales del gabinete nacional: "Se nos escucha y se nos da la seguridad de seguir siendo escuchados en armonía social, actuamos en forma coordinada con los trabajadores y los organismos estatales. Nuestros representantes participan de altos cuerpos consultivos forjados a iniciativa del Presidente de la Nación" (Gómez-Morales, 1954, p. 23).

Luego de renovados los convenios colectivos y ante el temor de que los empresarios trasladen costos a precios, en octubre de 1954 el gobierno lanzó el "Plan de Acción sobre el Equilibrio de la Economía Nacional”, que condensó la estrategia que se venía implementando desde 1952. El Estado asumía el rol, más modesto, de "orientador de la política monetaria y del crédito" y reafirmaba que el "éxito" de la política económica "no depende únicamente de él" sino de la "acción

${ }^{21}$ Respecto de los Consejos Regionales, véase Girbal Blacha (2000). 
coordinada" de todos los actores (Perón, 1954, p. 7). ${ }^{22}$ Respecto de la problemática de la productividad reclamada por los empresarios, el Plan mencionaba que la CGT había propuesto el Congreso de la Productividad y Bienestar Social, con el que "se persigue coordinar la acción de las fuerzas económicas con las del trabajo, para sentar las bases que sirvan de solución permanente a ciertos aspectos de la economía” (Perón, 1954, p. 12).

El líder peronista intentaba limitar a toda costa la posibilidad de una nueva carrera entre salarios y precios, por lo que apuntó todo su poder persuasivo a disuadir al actor obrero de que orientase su acción a presionar por una mayor participación en el ingreso. En este discurso, Perón argumentó que una "economía sin sobresaltos" era todo "cuanto el Estado ordenadamente puede asegurar". Y subrayó un factor que estaba "por sobre todos los demás":

Me refiero a la productividad. Organizada la economía y planificada la acción, nosotros podremos mejorar el estado de nuestras empresas y el estándar de vida de nuestro pueblo solamente produciendo más. [...] Si no producimos más, es inútil que tengamos ambiciones de ganar más y de estar mejor. Ese es un dilema de hierro en el que nuestra economía está encerrada. La economía que yo puedo darles, señores, es una economía organizada y conducida equilibradamente. Lo demás debe hacerlo el pueblo, los empresarios, los obreros y los consumidores (Perón, 2002, vol. 18.2, p. 432).

Así, queda claro que el gobierno esperaba que una vez garantizada la participación de la cGE en la economía, en el gobierno y en el Estado, fuesen los propios empresarios los que diesen la batalla por la productividad, librando al gobierno del costo político que ello implicaba. Ya en enero de 1954, en el acto de clausura de los Congresos Ordinario y Extraordinarios de la cGT, Perón apeló a la "responsabilidad" de trabajadores y empresarios: "aspiro a que estas organizaciones [...] reunidos en comisiones mixtas, establezcan las relaciones entre el capital y el trabajo, entre los precios y los salarios, entre las condiciones económicas y las sociales. [...] Es el pueblo mismo el que debe hacerse cargo y el que debe defender sus propios intereses” (Perón, 2002, vol. 18.1, p. 18).

En definitiva, no sería el gobierno peronista quien obligaría a los obreros a ajustar sus salarios en función de la productividad y del rendimiento. Es en este marco en donde debe ubicarse el Congreso Nacional de la Productividad y Bienestar Social (en adelante, CP), como la culminación de una estrategia basada en la cooperación económica y que buscaba delegar en los actores el problema de modificar el régimen de relaciones laborales. Como tal, era una apuesta a mediano y largo plazo.

Durante el Congreso, la cGE planteó que, si bien la legislación social peronista era legítima, la misma había sido objeto de abuso por parte de los trabajadores y que ello estaba en la base misma del problema de la productividad, del incremento de los costos y, en definitiva, del aumento de precios. De ahí que en las propuestas patronales se pueda notar un esfuerzo permanente por establecer normas precisas que delimitasen los abusos en la legislación social. ${ }^{23}$

La cuestión era por demás compleja, pues desde el punto de vista de los trabajadores tanto la legislación social peronista como las prácticas que acompañaban la vida diaria en las plantas fabriles eran parte del significado que atribuían a la "revolución peronista", concepción entroncada en el propio mundo del trabajo y que marcaba los parámetros de acción que los empresarios se proponían cambiar (Doyon, 2006; James, 2010). Uno de los temas más sustanciales y conflictivos del

${ }^{22}$ Respecto de este Plan, véase Rougier y Stawski (2013).

${ }^{23} \mathrm{Al}$ respecto, véanse Bitrán (1994) y Sowter (2016). 
CP fue la cuestión de los convenios colectivos. La forma que estos asumieron desde 1944 determinaron un aumento del poder de los trabajadores y una disminución de la capacidad patronal para organizar el trabajo. Un factor crucial dentro de la vida diaria de la empresa eran las comisiones internas, cuyo accionar afectaba la dinámica del proceso productivo.

La organización del Congreso refleja la lógica que asumió la cooperación económica desde 1952. La conformación de su estructura estaba basada en la paridad de representantes obreros y empresarios. El sistema de decisiones consistía en la unanimidad, lo cual garantizaba el control por parte de las dos entidades. El trabajo de todas las Comisiones derivarían en el "Acuerdo Nacional de Productividad y Bienestar Social”. Es decir que fuere cual fuere su contenido final, el Acuerdo comprometía a los actores y obligaba al Estado a observar su cumplimiento. El temario y su estructura reflejó la coincidencia de la agenda gubernamental con la empresaria, a saber: Tema I "Productividad: mejor nivel de vida"; Tema II "Medios concretos para elevar la productividad" y Tema III "Bases generales para acuerdos sobre productividad".

Finalmente, la CGE y la CGT firmaron el Acuerdo Nacional de Productividad (ANP). Si bien el CP en general ha sido caracterizado como un "fracaso" o un intento "fútil" por parte del gobierno (Bitrán, 1994, p. 270-271; Doyon, 2006, p. 390), desde el punto de vista de la estrategia política basada en la cooperación económica, hay algunos puntos que conviene destacar. Por un lado, se instaló socialmente la problemática de la productividad y se dejó por escrito el compromiso de ambas centrales a enfrentarlo. Por otro lado, tal como señalan Giménez-Zapiola y Leguizamón (1988), los actores debieron acordar cuestiones más allá de lo que estaban dispuestos a hacer. Por ejemplo, el punto III del ANP estableció que la empresa podría aplicar planes "para obtener un aumento de la productividad" y un "empleo racional e integral de la mano de obra disponible". Así, los empresarios lograron otro cometido: la facultad para reasignar de tareas al personal, algo que los convenios impedían. Por último, el punto Iv concretó uno de los principales objetivos de la CGE: los "incrementos directos en las remuneraciones por vía de incentivos proporcionados a la eficiencia del trabajador". ${ }^{24}$

\section{Conclusiones}

Este artículo se enfocó en un aspecto poco abordado en los estudios sobre la política económica peronista: la estrategia política formulada para reorientar las prioridades económicas en el marco de la crisis de los años 1949-1952. Las medidas previstas implicaban un cambio en la política económica que no sólo ponía en juego el apoyo sindical y popular al gobierno sino también el sentido de la propia identidad peronista. Los dilemas que esta situación suponía llevaron al gobierno a trazar una estrategia para lograr que la participación de los actores permitiera legitimar la reorientación de las políticas al tiempo que dotarlas de mayor efectividad. Herramienta fundamental de esta estrategia fue la cooperación económica, lo cual implicó un proceso en el que los consejos y comisiones económicas adquirieron mayor dinamismo y efectividad.

La reactivación de estos organismos respondió a dos factores: la disparada de los precios a partir 1949 y la necesidad de una estrategia política para enmarcar el "cambio de rumbo" de la política económica. En la medida que la crisis económica se agravó, que los controles de precios se mostraron insuficientes, que las restricciones crediticias impidieron subsidiar los aumentos sala-

${ }^{24}$ Reproducido en revista Hechos e Ideas (1955, pp. 363-367) 
riales y que el aumento de los costos fue trasladado a los precios, el gobierno diseñó una estrategia que puso en el centro a la cooperación económica para canalizar la participación de los actores, lo cual se dio a través de un proceso que presentó varios aspectos.

Primero, hubo una ampliación en las funciones y en los temas que se trataban. De la prioridad en el control de los precios, determinada por el gobierno, a la problemática de la producción, impulsada por los empresarios. Asimismo, se avanzó desde la función consultiva hacia la participativa, gracias a lo cual los empresarios empezaron a intervenir, en distinta medida, en las políticas de precios, crediticia, arancelaria, etc. Segundo, la necesidad de hacer efectiva la cooperación económica fue un factor importante que llevó a la definitiva conformación de la CGE, factor que no ha sido debidamente sopesado por la bibliografía. Una vez conformada la central, los empresarios buscaron plantear su propia agenda, lo cual pesó en el proceso de ampliación temática. Tercero, las discusiones revelan la transformación que se buscó operar en el rol del Estado y de los actores socioeconómicos, lo cual implicó un cambio en el modelo de gobernabilidad de la economía que imperaba desde 1946. Y, cuarto, si bien la falta de continuidad de los organismos creados hace que la institucionalización de la cooperación económica haya sido débil, errática y oscilante, no menos cierto es su persistencia y continuidad.

A partir de la Comisión de Precios y Salarios de 1952, quedó claro que el gobierno esperaba que fueran los mismos actores los que acordaran y propusiesen las medidas que luego el gobierno ejecutaría. Esto implicaba un proceso de negociación entre empresarios y trabajadores que los obligaba a hacer concesiones mutuas y los comprometía a respetar lo acordado. El contrapunto entre el gobierno y la CGT permite observar que lo que estaba en juego era en cierta medida hasta qué punto el gobierno peronista estaba atado o no a un determinado modelo económico y de relaciones laborales.

Desde el punto de vista de su estrategia política, el gobierno esperaba que una vez garantizada la participación de la CGE en la economía, en el gobierno y en el Estado, fuesen los propios actores los que librasen la batalla por la productividad, eximiendo al gobierno del costo político que ello implicaba. En definitiva, no sería Perón quien obligaría a los obreros a ajustar sus salarios en función de la productividad y del rendimiento. Esta fue la estrategia que explica la iniciativa del Congreso de la Productividad, y como tal, era una apuesta a mediano y largo plazo, razón por la cual resulta fútil evaluar su impacto.

Por último, el estudio de la cooperación económica lleva a una caracterización más matizada acerca de la política económica peronista. La idea de "aislamiento" debe ser repensada en la medida en que se observa que los consejos y comisiones lograron una mayor participación de los empresarios a partir de 1952. Por otra parte, respecto de su grado de "autonomía”, se observa una disminución de la misma respecto del contexto económico, nacional e internacional, el cual impuso fuertes restricciones. Sin embargo, no se puede decir lo mismo en relación con los actores socioeconómicos, frente a los cuales el gobierno siguió manteniendo grados considerables de autonomía, algo que queda demostrado en la operatoria de los consejos y comisiones, pues era el gobierno quien establecía el temario y las condiciones bajo las cuales surgían los acuerdos. Es en este sentido que la cooperación económica se reveló como una herramienta más sofisticada tanto para legitimar la reorientación de la política económica como para lograr una mayor efectividad en ciertos aspectos de esta. 


\section{REFERENCIAS BIBLIOGRÁFICAS}

Acuña, C. H. (2014). El peronismo que no fue: El papel de la lucha política inter-industrial en la temprana frustración del peronismo de Perón (Núm. IIEP, 4; pp. 1-66). Buenos Aires, Argentina: Instituto Internacional de Economía Política de Buenos Aires. Recuperado de https://ri.conicet.gov.ar/h andle/11336/8641

Banco Central de la República Argentina (1952). La política monetaria y crediticia al servicio del desarrollo económico de la República Argentina. Buenos Aires: Autor.

Belini, C. (2014). Convenciendo al capital: Peronismo, burocracia, empresarios y política industrial, 19431955. Buenos Aires: Imago Mundi.

Berrotarán, P. M. (2003). Del plan a la planificación: El estado durante la epoca peronista. Buenos Aires: Imago Mundi.

Bitrán, R. (1994). El Congreso de la Productividad. Buenos Aires: El Bloque.

Brennan, J. P. y Rougier, M. (2009). The politics of national capitalism: Peronism and the Argentine bourgeoisie, 1946-1976. Pensilvania: Pennsylvania State University Press.

Comisión Nacional de Precios y Salarios (1952). Actualización de los niveles de vida y de salarios al mes de diciembre de 1952. Buenos Aires: Autor.

Consejo Económico Nacional (1949a). Plan de acción en materia económica. Buenos Aires: Autor.

Consejo Económico Nacional (1949b). Situación económico-financiera del país. Buenos Aires: Autor.

Consejo Económico Nacional (1951). Situación económica actual y perspectivas para 1952. Buenos Aires: Autor.

Consejo Económico Nacional (1952). Equilibrio de precios y salarios (vols. 1-11). Buenos Aires: Autor.

Cúneo, D. (1984). Comportamiento y crisis de la clase empresaria. Buenos Aires: Centro Editor de América Latina.

Dijk, T. A. van (ed.). (2000). El discurso como interacción social. Barcelona: Gedisa.

Doyon, L. M. (2006). Perón y los trabajadores: Los orígenes del sindicalismo peronista, 1943-1955. Buenos Aires: Siglo XXI.

El Acuerdo Nacional de la Productividad y la creación del Instituto (1955). Hechos e Ideas, 132.

Elena, E. (2011). Dignifying Argentina: Peronism, Citizenship, and Mass Consumption. Pittsburgh: University of Pittsburgh Press. DOI: 10.2307/j.ctt5hjp79

Gerchunoff, P. y Llach, L. (2003). El ciclo de la ilusión y el desencanto: Un siglo de políticas económicas argentinas. Buenos Aires: Ariel.

Germani, G. (1968). Política y sociedad en una época de transición: De la sociedad tradicional a la sociedad de masas. Buenos Aires: Editorial Paidós.

Giménez-Zapiola, M. G. y Leguizamón, C. M. (1988). La concertación peronista de 1955: El congreso de la productividad. En L. M. Doyon y J. C. Torre (eds.), La Formación del sindicalismo peronista. Buenos Aires: Editorial Legasa.

Girbal-Blacha, N. (2000). El cambio de rumbo de la economía argentina peronista (1949-1955). El crédito agrario y los consejos regionales de promoción. Ciclos en la historia, la economía y la sociedad, 10(20), 3-26.

Gómez-Morales, A. (1953). Situación económica argentina. Horizontes Económicos, 9(92).

Gómez-Morales, A. (1954). La organización de las fuerzas económicas y la función de gobierno. Buenos Aires: El Ministerio. 
James, D. (2010). Resistencia e integración: El peronismo y la clase trabajadora argentina 1946-1976. Buenos Aires: Siglo XXI.

Jáuregui, A. (2004). Brasil y Argentina: Los empresarios industriales, 1920-1955. Buenos Aires: Imago Mundi.

Luna, F. (1986). Perón y su tiempo. Buenos Aires: Sudamericana.

Mainwaring, S. (1986). The state and the industrial bourgeoisie in peron's Argentina, 1945-1955. Studies in Comparative International Development, 21(3), 3-31. DOI: 10.1007/BF02717379

Mallon, R. D., y Sourrouille, J. V. (1973). La política económica en una sociedad conflictiva: El caso argentino. Buenos Aires: Amorrortu.

Novick, S. (2004). IAPI: Auge y decadencia. Buenos Aires: Catálogos.

Peralta-Ramos, M. (2007). La economía política argentina: Poder y clases sociales (1930-2006). Buenos Aires: Fondo de Cultura Económica.

Perón, J. D. (1950). Constitución de la Comisión Nacional de Cooperación Económica. Una etapa más en la ejecución de la doctrina peronista en el orden económico. Buenos Aires: Secretaría de Informaciones.

Perón, J. D. (1954). Puntos de vista del Gobierno y Estado Nacional para iniciar, de inmediato, la ejecución del Plan de Acción sobre el Equilibrio de la Economía Nacional. Buenos Aires: Secretaría de Prensa y Difusión.

Perón, J. D. (1997). Obras completas. Buenos Aires: Docencia.

Perón, J. D. (2000). Obras completas. Buenos Aires: Docencia.

Perón, J. D. (2002). Obras completas. Buenos Aires: Docencia.

Presidencia de la Nación (1953). Segundo Plan Quinquenal. Buenos Aires: Subsecretaría de Informaciones.

Rapoport, M. (2000). Historia económica, política y social de la Argentina (1880-2000). Buenos Aires: Ediciones Macchi.

Revestido, M. (1954). Las finanzas y la organización económica. Buenos Aires: Ministerio de Finanzas.

Rougier, M. (2001). La política crediticia del Banco Industrial durante el primer peronismo (19441955). Buenos Aires: Universidad de Buenos Aires.

Rougier, M. (2012). La economía del peronismo: Una perspectiva histórica. Buenos Aires: Editorial Sudamericana.

Rougier, M. N. y Stawski, M. (2013). Un programa que 'no puede conformar a todos': Economía y burocracia en los años finales del primer peronismo. América Latina en la Historia Económica, 21(1), 174-199. DOI: 10.18232/alhe.v21i1.563

Rougier, M. y Sowter, L. (2018). La Comunidad Organizada y los empresarios industriales. En R. Rein y C. Panella (eds.), En busca de la Comunidad Organizada. Organizaciones políticas, sociales, económicas y culturales del primer peronismo. San Justo: Universidad Nacional de La Matanza.

Schiavi, M. (2013). El poder sindical en la Argentina peronista: 1946-1955. Buenos Aires: Imago Mundi.

Sidicaro, R. (2002). Los tres peronismos: Estado y poder económico 1946-1955, 1973-1976, 19891999. Buenos Aires: Siglo Veintiuno Editores.

Sowter, L. (2014). De la participación a la colaboración: La institucionalización de la cooperación empresaria en la emergencia del peronismo, 1943-1946. Papeles de trabajo: La revista electrónica del IDAES, 8(14), 116-137. 
Sowter, L. (2015). El Consejo Económico y Social y la política de la cooperación económica en los primeros años de la Argentina peronista, 1946-1948. Revista Escuela de Historia, 14(1), 1-18.

Sowter, L. (2016). La experiencia del Congreso de la Productividad y la política de la cooperación económica durante el peronismo. Temas y Debates, 20(32), 135-154.

Stawski, M. (2012). De los Consejos al Ministerio. La gestión de la economía y las transformaciones de la trama burocrática estatal bajo el peronismo (1946-1955) (Tesis doctoral). Universidad de Buenos Aires, Argentina.

Teichman, J. (1981). Interest Conflict and Entrepreneurial Support for Peron. Latin American Research Review, 16(1), 144-155.

Villarruel, J. C. (1988). El Estado, las clases sociales y la política de ingresos en los gobiernos peronistas, 1946-1955. En M. Rapoport, E. Azcuy Ameghino, R. Prebisch, C. Taylor y F. J. Weil (eds.), Economía e historia: Contribuciones a la historia económica argentina. Buenos Aires: Editorial Tesis.

Archivos

AGN Archivo General de la Nación.

Hemerografía

La Nación, 1951, 1952, 1953 diario periódico de la Capital Federal. 